\title{
锂电诺奖与科学精神
}

黄云辉 ${ }^{*}$

华中科技大学材料科学与工程学院, 武汉 430074

摘要: 2019 年诺贝尔化学奖授予了约翰·古迪纳夫、斯坦利·惠廷厄姆和吉野彰三位科学家, 以表彰他们在锂离子电池领 域做出的重要贡献。经过 40 余年的发展, 锂离子电池已经被广泛应用于人类生产、生活的方方面面, 这离不开全世界 千千万万科技工作者的创造、探索和实践。本文结合此次锂电诺奖特别是古迪纳夫教授的故事，阐述创新、求实、交叉、 合作的科学精神及其对科学研究和人才培养的重要性。

关键词: 2019 年诺贝尔化学奖; 锂离子电池; 科学精神; 创新求实; 交叉合作

中图分类号: G64；O6；TM912

\section{Nobel Prize for Lithium-Ion Battery and the Scientific Spirit}

\section{Yunhui Huang *}

School of Materials Science and Engineering, Huazhong University of Science and Technology, Wuhan 430074, P. R. China.

\begin{abstract}
The 2019 Nobel Prize in Chemistry was rewarded to three scientists, John B. Goodenough, M. Stanley Whittingham and Akira Yoshino, for their great contribution in the field of lithium-ion batteries. After more than 40 years' development, lithium-ion batteries have been widely used in our daily life, which is inseparable from the creation, exploration and hard work of millions of scientists all over the world. This paper expatiates the scientific spirit of innovation, pragmatism, interdiscipline and cooperation, and demonstrates the importance for scientific research as well as talents cultivation from the views of the stories of the Nobel laureates especially of Professor Goodenough.
\end{abstract}

Key Words: 2019 Nobel Prize in Chemistry; Lithium-ion battery; Scientific spirit; Innovation and pragmatism; Interdiscipline and cooperation

2019 年 12 月 10 日, 一年一度举世瞩目的诺贝尔奖颁奖典礼在瑞典斯德哥尔摩举行, 诺贝尔化 学奖授予了为锂离子电池的发展做出了杰出贡献的三位科学家: 美国德克萨斯大学奥斯汀分校约 翰·古迪纳夫(John B. Goodenough)、美国纽约州立大学宾汉姆顿分校斯坦利·惠廷厄姆(M. Stanley Whittingham)和日本旭化成公司吉野彰(Akira Yoshino) ${ }^{[1]}$ 。这三位科学家的获奖可以说是众望所归。

我们知道, 锂离子电池在我们生活当中发挥着越来越重要几乎无可替代的作用, 大家每天用的 手机、笔记本电脑等离不开它, 越来越普及的新能源汽车离不开它, 太阳能、风能等新能源所需的 规模储能也离不开它, 未来智能社会的发展更需要它的助推和牵引。三位科学家为锂离子电池的发 展做了原创性的工作：惠廷厄姆在 20 世纪 70 年代发现了由二硫化钛为正极、金属锂为负极的可充 电的二次锂电池 ${ }^{[2-4]}$; 古迪纳夫于 1980 年采用金属氧化物钴酸锂为正极、同样以金属锂为负极构筑 
了新型二次锂电池, 开路电压达到 4 伏 ${ }^{[5,6]}$; 吉野彰则于 1985 年发现可容纳锂离子的焦炭替代金属 锂做负极, 并开发了首个接近商用的锂离子电池 ${ }^{[7]}$ 。他们三人所开发的正负极材料都是基于锂离子 嵌入和脱出的新机制, 为 1991 年日本索尼公司第一个商用锂离子电池的问世和锂离子电池的进一 步发展奠定了基础。当然, 锂离子电池是一个复杂的电化学器件, 涉及的材料种类繁多, 除对电化 学性能起决定性作用的正负极材料外, 还包括隔膜、电解液、集流体以及其它辅助材料, 另外单体 电池制备工艺、电池成组技术以及热管理和电池管理系统等同样具有非常重要的作用。可以说, 锂 离子电池是学术界、产业界成千上万的科技工作者集体智慧的结晶。就中国而言, 目前无论是锂离 子电池的产量还是市场都已居于全球首位, 中国有全球最多的手机使用者, 也有全球最大的新能源 汽车应用市场, 锂离子电池直接的市场份额已达到 2000 亿元人民币, 新能源汽车去年的销售量就突 破 100 万辆, 另外中国从事锂离子电池及其相关行业的科技工作者数量也是全球之最, 无论论文数 量还是专利数量均不亚于其它任何国家, 可以说中国为锂离子电池的发展做出了巨大贡献。锂电诺 奖的授予既是对锂离子电池的发展所给予的高度肯定, 也必将促进锂离子电池及其相关领域的进一 步发展。我们在感恩诺奖得主及广大科技工作者为锂离子电池发展做出重要贡献从而给人类生活带 来深刻变革的同时, 也为此次诺奖所折射出的创新、求实、交叉、合作的科学精神所叹服。作者曾 于 2004 至 2007 年师从古迪纳夫先生从事博士后研究, 本文主要阐述此次诺奖所折射的科学精神, 并更多地结合他的故事展开。

\section{1 创新是科学之魂}

创新是科学之魂, 没有创新就没有科技的发展, 也没有锂离子电池的诞生。在锂离子电池问世 之前, 人们所用的可充电电池体系主要包括铅酸电池、镍氢电池等, 它们都是基于在电极上发生氧 化还原电化学反应的机制, 电压均不超过 2 伏, 人们迫切需要寻找电压更高、能量密度更大的二次 电池体系。锂是元素周期表中最轻的金属元素, 同时其还原电位最低, 在同等重量或体积下锂电池 可储存更大的能量 ${ }^{[8]}$ 。基于锂离子在电极材料中嵌入和脱出的机制构筑二次电池可满足以上要求, 但是否可行呢?

20 世纪 70 年代初期, 人们在研究硫化物超导材料时发现, 有机或无机小分子可嵌入到 $\mathrm{NbS}_{2}$ 、 $\mathrm{TaS}_{2}$ 等材料中, 而且嵌入分子的不同会导致超导临界温度 $\left(T_{\mathrm{c}}\right)$ 的相应变化 ${ }^{[9]}$ 。惠廷厄姆发现 $\mathrm{TiS}_{2}$ 可以 可逆地嵌入和脱出锂离子, 他巧妙地将这种嵌入型材料应用于二次电池中, 以 $\mathrm{TiS}_{2}$ 为正极、金属锂 为负极构筑了二次锂电池 ${ }^{[2-4]}$ 。古迪纳夫发现 $\mathrm{Li}_{1-x} \mathrm{CoO}_{2}$ 同样可以嵌入和脱出锂离子, 而且以金属锂 为负极能够产生更高的开路电压, 比能量密度可达 $\mathrm{TiS}_{2}$ 的 2 倍之多 ${ }^{[5,6]}$ 。吉野彰发现碳材料做负极亦 可脱嵌锂离子, 配以钴酸锂正极, 采用有机电解液, 可获得 4 伏的电压, 从而制备出锂离子电池的 雏形 ${ }^{[7]}$ 。这几位科学家的发现都是原创性的成果, 首先他们提出的锂离子嵌入和脱出的机制是新的, “锂离子电池” 的概念也是新的, 再者, 用于二次锂电池的钴酸锂、二硫化钛正极材料以及碳负极 材料在当时都是新型电极材料, 所构筑的锂离子电池雉形在当时完全是全新的电化学体系。当然, 这其中也离不开电解液、隔膜等材料的贡献。

由锂离子电池的发明我们可以看到, 创新是魂, 是精髓所在。但创新绝不是空穴来风, 没有前 人的基础, 没有创新者本人长期的知识和科研的积累是难以做到的。以古迪纳夫为例, 他之所以能 够发现钴酸锂, 与他长期从事凝聚态物理领域的研究是分不开的, 他当时之所以敢于提出金属氧化 物体系比硫化物体系更适合于做脱嵌锂离子的正极材料, 正是基于他对于金属氧化物体系的结构、 物理性能特别是对能带理论的透彻理解。继 1980 年发现钴酸锂之后, 他又于 1984 年发现另一重要 的正极材料锰酸锂 ${ }^{[10-12]}$, 更为神奇的是时隔 13 年之后的 1997 年, 他在 75 岁的时候还能发现另一 


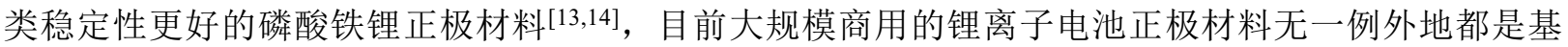
于他的原创。人们不禁要问, 为什么他能具备和保持如此强劲和旺盛的创新能力?

在师从古迪纳夫先生三年多的时间里, 本人切身体会到他的创新精神。除了上述他具有扎实的 理论知识外, 他对于科研的创新追求情有独钟。对任何问题都有敏锐的思考, 不仅体现在他活跃的 思维, 更体现在他对创新的坚持。基于对科学问题本质深层次的理解, 无论是锂离子电池、固体氧 化物燃料电池, 还是超导和磁电阻材料, 他总能提出一些新的见解, 去预见一些新的材料体系。一 旦有了新的想法, 他会主动找学生或博士后进行讨论, 深入浅出地说明他的想法的可行性。记得和 他一起工作的那段时间里, 他经常找我讨论锂离子电池或固体氧化物燃料电池的一些新的想法, 但 几乎每次都比较失望, 要么这种材料早就有报道, 要么实验结果表明没有性能或性能很差。即使这 样, 他仍然能够继续探索新思想, 不断地去寻找或预见一些新材料, 当然大多仍然是以失败而告终。 每次我觉得沮丧之时, 总能被他爽朗的笑声所鼓舞。有时我想, 大概正是由于他的这种坚持, 反复 失败反复思考又反复地去试验, 即使经历 100 次的失败, 总能有一两次的成功吧。也许正因为有这 一两次的成功, 才造就了钴酸锂、锰酸锂和磷酸铁锂! 对于我们从事化学和材料领域研究的科技工 作者来说, 创新应该是我们工作的原动力, 无论是新的理论或机理, 还是新的化学或材料体系, 无 论是新的制备方法还是新的结果, 无论是大创新还是小创新, 我们都应该认真去把握, 应该把创新 精神融入到我们学习和研究的每一个环节之中。

\section{2 求实是科学之据}

求实为创新提供是否可行的依据, 没有结果的创新是空洞的创新, 而结果的产生离不开实践。 我的博士导师徐光宪先生经常和我们谈及科研的创新, 他提倡 “学而问, 问而思, 思而行, 行而果”, 也就是说, 我们在学习的同时必须要提出问题, “学而不问则殁, 问而不学则罔”, 提出问题后再 去认真思考, 凝练出一些创新的思路, 有了思路还是不够的, 必须通过大量的实验去探索, 去取得 结果。

从此次诺奖成果并结合锂离子电池的发展我们可以清楚地看到, 锂离子脱嵌新机理、钴酸锂正 极和碳负极新的电极材料、锂离子电池的倠形等, 都是通过大量的实验进行了反复的验证, 从学术 界到产业界不断地进行深入研发、优化、拓展, 才有了我们今天对锂离子电池全方位的了解、掌握 和应用, 才有了其在手机、电动汽车、储能领域的大规模商用。在锂离子电池发展的过程中, 不断 地有新的电极材料的提出, 大量的基础实验甚至小试、中试等工程试验去验证了它们的可行性, 但 到目前为止尚没有一种正极材料具有古迪纳夫先生发现的钴酸锂、锰酸锂、磷酸铁锂那样强大的生 命力。

实践可以存真, 实践也可以去伪。古迪纳夫先生非常重视实践的作用, 虽然他本人不可能亲自 去做实验, 但他对于每一个研究工作的实验细节都非常关心, 包括实验方案、制备方法、表征手段、 结果分析等, 他经常主动来找我们学生讨论。每次我把整理好的文章交给他时, 他首先要询问实验 细节, 确认实验数据是否可靠, 然后总会问一句 “你是希望我大改还是小改”。所谓 “大改” , 就 是根据实验结果, 按照他的思路重新整理; 所谓 “小改” , 就是帮助理顺文章的逻辑结构并润色语 言。当然 “大改” 和 “小改” 都是基于实验数据完全可靠的前提下。为了不让老先生花费过多的时 间和精力, 我几乎每次都会说希望 “小改” , 但有时实在 “看不下去”, 他还是要 “大改”。每次 他对文章的修改都细致入微, 由学生或秘书打印出来, 在纸质版本上逐字逐句修改, 学生们根据他 的手迹修改后的版本他还要进一步审核。 
求实是一个严谨的过程, 来不得半点虚假, 要经得起时间和空间的检验。“时间” 是科学创新 最好的试金石, 任何理论和方法都要经得起时间的考验。锂离子电池从 20 世纪 70 年代的原始概念、 到 1991 年日本索尼公司第一只商用电池的问世、再到今天深入到我们生活的方方面面, 历经 40 余 载, 虽然它还不够十全十美, 能量密度、功率密度、安全性、寿命、成本等主要技术指标不能完全 满足人们越来越高的需求, 全球数以万计的科技工作者前赴后继不断努力, 目前更多地致力于更安 全的固态电池、能量密度更高的锂硫和锂空气等下一代电池、成本有望更低的钠离子电池等的研发， 相信诺奖得主们开创的可充电的世界将变得越来越完美。所谓 “空间” , 科学应该是无国界的, 但 同时也需要充分尊重知识产权。锂离子电池从它诞生之日起就引起了高度关注, 全球学术界和产业 界均投入了大量的人力物力, 为它的发展壮大做出了重要贡献, 可以说锂离子电池是人类共同的财 富。锂离子电池应用性很强, 不仅科学问题需要凝练和解决, 材料合成、电芯制备、电池成组、管 理系统等技术问题也同时需要攻克, 技术和科学同等重要, 专利与论文也同等重要。三位诺奖得主 均十分重视专利的申请, 他们的原创性发明就包含着专利 ${ }^{[3,6,7,14]}$, 锂离子电池的发展也离不开数以 万计的专利的贡献。

\section{3 交叉是科学之基}

锂离子电池本身涵括的领域众多, 涉及的学科也不少, 包括化学、材料、物理、机械、信息甚 至数学等。锂离子电池的发展离不开学科交叉, 需要不同学科的高度融合, 才能催生新理论和新技 术。古迪纳夫先生本科毕业于耶鲁大学数学系、博士毕业于芝加哥大学物理系, 后在麻省理工学院 林肯实验室从事凝聚态物理方面的研究工作, 在超导和磁电阻材料领域取得过突出的成就, 参与开 发了第一个随机存取存储器 ${ }^{[15]}$, 提出了确定材料磁性超交换的 Goodenough-Kanamori 规则 ${ }^{[16,17]}$, 发

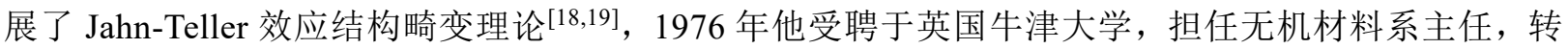
行从事储能材料研究。惠廷厄姆学的专业是化学, 但他从 1972 年到 1984 年在埃克森美孚公司研究 电池材料, 从事与工程应用相关工作, 后来在美国纽约州立大学宾汉姆顿分校担任材料研究所项目 主管。吉野彰毕业于京都大学大学院工学研究专业, 毕业后直接进入旭化成公司, 主持项目研发。 从这几位诺奖得主的履历我们可以看到, 他们的专业跨度都比较大, 涉及化学、材料、物理、工程 等学科, 丰富的研究背景使得他们在从事锂离子电池研究时开发新材料、构筑新型电池都游刃有余。

古迪纳夫先生非常重视学科的交叉, 在他的课题组中, 除了锂离子电池研究方向外, 也有固体 氧化物燃料电池 (SOFC) 以及凝聚态物理, 大家可以经常在一起讨论, 交流思想。其实, 这几个方向 从材料的合成、表征、性能都有相似甚至相同之处, 材料的结构和能带价带几乎异曲同工。他在招 收博士后时也特别看重交叉的背景。记得 2004 年我申请他的博士后时, 他看过我简历后很爽快地就 答应了。我本科学的是化学, 硕士时师从高小霞先生从事电分析化学研究, 博士时师从徐光宪先生 和严纯华教授从事稀土无机功能材料的研究, 从 1997 到 2004 年一直研究钻针矿氧化物磁电阻材料, 属凝聚态物理的范畴, 而当时古迪纳夫先生也正在从事钙钛矿磁电阻材料的研究, 但他建议我转行 做能源材料, 而这恰恰是我求之不得的。正是因为之前我多年从事氧化物庞磁电阻材料特别是 $\mathrm{Sr}_{2} \mathrm{FeMoO}_{6-\delta}$ 双钻钛矿材料的研究, 深知这类材料具有很好的电子导电性, 并且由于氧缺位的存在, 可作为氧离子的传导体, 另外 $\mathrm{Mo}^{6+} / \mathrm{Mo}^{5+}$ 氧化还原对可很好地催化氧化甲烷等碳氢化合物燃料, 因 此 “移花接木” 地用来做 SOFC 的阳极材料, 获得了很高的功率密度, 并且可直接用于以甲烷为燃

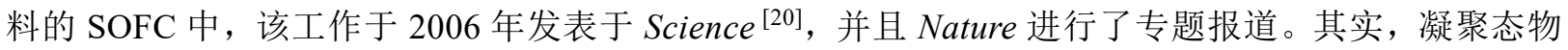
理方面的知识和成果很多可以借鉴或应用于能源材料与器件领域的研究中。 


\section{4 合作是科学之路}

此次锂电诺奖实至名归, 颁奖典礼上三位获奖者手握手的镜头让人感慨万千。从原理到正负极 材料再到器件, 三人像传递接力棒一样, 为锂离子电池的诞生各自贡献一份力量, 缺一不可, 锂离 子电池进一步发展又凝聚着千百万科技工作者的智慧和汗水。没有他们在时间和空间上的紧密合作， 不可能有锂离子电池的今天。科技越是高度发达, 越需要人们为了共同的目标通力合作, 个人的力 量始终是有限的, 团结合作的力量才是强大的。姑且不说大层面上的国际和国内的合作, 就是不同 团队之间、同一团队中每个人之间的合作都是走向成功的必由之路。我们需要具备合作精神, 同时 更需要营造合作的氛围和文化。古迪纳夫先生在发现正极材料的过程中, 正是有不少的学生和博士 后等在他的领导和指导下, 解决一个个科学难题, 攻克一个个技术壁垒, 才有了钴酸锂、锰酸锂和 磷酸铁锂, 例如, K. Mizushima ${ }^{[5]}$ 等为发现钴酸锂做了贡献, M. M. Thackeray 和 P. G. Bruce 等 ${ }^{[11,12]}$

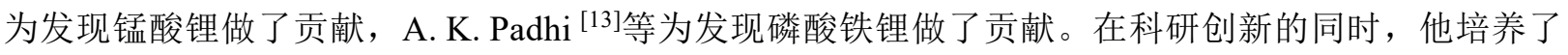
一批又一批电池及凝聚态领域的杰出人才, 其中不乏业界著名学者, 如 M. M. Thackeray、 P. G. Bruce、 A. Manthiram 等锂电大家, 他培养的中国学生、博士后和访问学者也不少, 分布在高校和企业, 他 在学术领域与中国学者也有着密切的合作。

2019 年诺贝尔奖的帷幕已慢慢落下, 但诺奖得主们的精彩故事还将流传, 特别是他们的科学精 神将永远给人们以鼓舞和激励。在这里, 我还想再次提及古迪纳夫先生, 他的传奇人生铸就了辉煌, 虽已 97 岁高龄, 但他仍壮心不已, 他敏捷的思维始终伴随着他的创新精神迸发着灿烂的火花, 他从 斯德哥尔摩回到奥斯汀后, 那爽朗的笑声又将回荡在德州大学机械大楼的办公室、实验室和整个楼 道; 他计划再工作五年, 或许五年之后他还将宝刀不老地带着孙子辈、曾孙辈们为解决电池的安全 问题而继续奋斗; 他淡泊名利, 几乎所有的奖金都捐献给社会, 甚至博士后的工资有的都是用他自 己的薪水支付; 他追求的是科学, 是一种永恒的精神, 一种为人类社会能够竭力奉献的精神, 他必 将书写一段人类科学史上不老的传奇!

\section{参 考 文 献}

[1] Nobel Prizes. [2019-03-05]. https://www.nobelprize.org/all-2019-nobel-prizes/.

[2] Whittingham, M. S.; Gamble, F. R., Jr. Mater. Res. Bull. 1975, 10 (5), 363.

[3] Whittingham, M. S. Batterie à Base de Chalcogénures: Belgian Patent, 819672. 1975-03-09.

[4] Whittingham, M. S. Science 1976, 192 (4244), 1126.

[5] Mizushima, K.; Jones, P. C.; Wiseman, P. J.; Goodenough, J. B. Mater. Res. Bull. 1980, 15 (6), 783.

[6] Goodenough, J. B.; Mizushima, K. Fast Ion Conductors: U. S. Patent, 4357215. 1982-11-02.

[7] Yoshino, A.; Sanechika, K.; Nakajima, T. Secondary Battery: U. S. Patent, 4668595. 1987-05-26.

[8] Winter, M.; Barnett, B.; Xu, K. Chem. Rev. 2018, 118 (23), 11433.

[9] Gamble, F. R.; Osiecki, J. H.; Cais, M.; Pisharody, R.; DiSalvo, F. J.; Geballe, T. H. Science 1971, 174 (4008), 493.

[10] Thackeray, M. M.; David, W. I. F.; Goodenough, J. B. Mater. Res. Bull. 1982, 17 (6), 785.

[11] Thackeray, M. M.; David, W. I. F.; Bruce, P. G.; Goodenough, J. B. Mater. Res. Bull. 1983, 18 (4), 461.

[12] Thackeray, M. M.; Johnson, P. J.; De Picciotto, L. A.; Bruce, P. G.; Goodenough, J. B. Mater. Res. Bull. 1984, 19 (2), 179.

[13] Padhi, A. K.; Nanjundaswamy, K. S.; Goodenough, J. B. J. Electrochem. Soc. 1997, 144 (4), 1188.

[14] Goodenough, J. B.; Padhi, A. K.; Nanjundaswamy, K. S.; Masquelier, C. Cathode Materials for Secondary (Rechargeable) Lithium Batteries: U. S. Patent, 5910382. 1999-06-08.

[15] Menyuk, N.; Goodenough, J. B. J. Appl. Phys. 1955, 26, 8. 
[16] Goodenough, J. B. Phys. Rev. 1955, 100, 564.

[17] Goodenough, J. B. J. Phys. Chem. Solids 1958, 6, 287.

[18] Goodenough, J. B. J. Phys. Chem. Solids 1964, 25, 151.

[19] Goodenough, J. B. Annu. Rev. Mater. Sci. 1998, 28, 1.

[20] Huang, Y. H.; Dass, R. I.; Xing, Z. L.; Goodenough, J. B. Science 2006, 312, 254.

\section{【作者简介】}

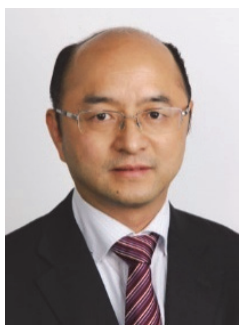

黄云辉, 2000 年在北京大学获得理学博士学位。现为华中科技大学学术委员会副主任, 同济大 学兼职教授, 教育部 “长江学者” 特聘教授, 国家杰出青年科学基金获得者。曾在日本东京工业大 学、美国德克萨斯大学奥斯汀分校从事博士后研究, 师从诺贝尔奖得主 John B. Goodenough 教授。 2008 年回国到华中科技大学工作, 2010-2017 年任材料科学与工程学院院长。主要研究领域为能源 材料, 包括锂离子电池、下一代电池、钠离子电池、固体氧化物燃料电池, 在 Science、Energy Environ. $S c i$ 、A $d v$. Mater 等国内外学术期刊上, 发表学术论文 400 余篇, 引用 2.5 万余次, 入选科点唯安全 球材料领域高被引科学家(2018、2019), 授权或公开专利 30 余项。研发成果已在华为、上汽、宝钢、 万润等企业获得应用, 获国家自然科学二等奖 1 项。 